\title{
THE MECHANICS OF INFLATABLE ANCHORS IN COHESIONLESS SOIL
}

\author{
Tim Newson ${ }^{\text {i) }}$, SeAn Hinchberger ${ }^{\text {ii) }}$ and Yi Liang ${ }^{\text {iii) }}$
}

\begin{abstract}
This paper describes an investigation into the performance and pullout capacity of an inflatable anchor system. The anchor system comprises a hydraulically inflated rubber membrane or packer that may be bored into place and then inflated to provide pullout resistance. A series of scaled physical model tests were used to study the anchor performance and pullout capacity. The model tests were done in a calibration chamber using cohesionless sand and anchors of various length, diameter, embedment depth and inflation pressure. The anchor behaviour during pullout is interpreted using finite element analysis that accounts for non-linear soil behaviour, inflation and subsequent deformation of the inflatable membrane, and anchor-soil interaction. The scaled model tests and interpretations assist with identifying the dominant mechanisms affecting the pullout capacity of inflatable anchor systems.
\end{abstract}

Key words: Finite Element Method, inflatable anchor, pullout capacity, sand (IGC: E4)

\section{INTRODUCTION}

Many remote operated vehicles (ROVs) are neutrally or positively buoyant. Consequently, utilizing an ROV for offshore activities such as in situ testing or maintaining pipelines may require anchorage of the ROV to control or limit its movement. Previous attempts to use 'classical' anchor systems such as helical screws, and suction, duckbill or plate anchors have had variable success. Many of these anchor systems are difficult to deploy and they take away from the payload capacity of the ROV. Consequently, an inflatable anchor system that is inexpensive, reusable and has several uses would be desirable for offshore applications.

This paper describes an investigation into the mechanics of inflatable anchor systems. A series of scaled physical model pullout tests were done in a calibration chamber using dry cohesionless sand and anchors of various length, diameters, embedment depth and inflation pressures. The anchor behaviour during the pullout tests is interpreted using the finite element (FE) program PLAXIS. The FE model accounts for non-linear soil behaviour, anchor inflation, deformation of the inflatable membrane and soil-anchor interaction. The scaled physical model tests in conjunction with the FE analyses help to identify the factors affecting the pullout capacity of this type of anchor system. It is shown that, for a given soil condition, the anchor pullout capacity is a function of embedment, effective length and the degree of cavity expansion during anchor inflation. The improved understanding obtained from this study should assist with the development of anchor capacity diagrams for use in offshore applications.

\section{EXPERIMENTAL STUDY}

\section{Equipment}

Reduced scale physical model testing was carried out in a large cylindrical steel test chamber of $700 \mathrm{~mm}$ internal diameter and $1200 \mathrm{~mm}$ height (Newson et al., 2003). Figure 1 shows the test apparatus and setup.

A typical test consisted of an initially "wished-inplace" inflatable anchor in sand followed by inflation of the anchor and a pullout tests. A three-phase motor attached to a gearbox (200:1 gearing ratio) and screw jack was used to pull out each anchor. The motor was computer controlled permitting different pullout rates to be applied. The pullout rate was held constant during each test. Anchor head displacement was measured using a linear voltage displacement transducer (LVDT) mounted on the same load frame as the screw jack (see Fig. 1) and resting on the anchor head.

Axial load was measured using a $2.5 \mathrm{kN}$ load cell connected to the screw jack and anchor head. The pullout load and anchor head displacement were both recorded using a computer controlled data acquisition system. The anchor was inflated with water using two screw pumps equipped with LVDTs to measure the pump displacement

i) Associate Professor, Geotechnical Research Centre, Department of Civil and Environmental Engineering, The University of Western Ontario, Canada.

ii) Associate Professor, ditto (shinchberger@eng.uwo.ca).

iii) Ph.D Student, ditto.

The manuscript for this paper was received for review on August 30, 2007; approved on March 26, 2009.

Written discussions on this paper should be submitted before January 1, 2010 to the Japanese Geotechnical Society, 4-38-2, Sengoku, Bunkyo-ku, Tokyo 112-0011, Japan. Upon request the closing date may be extended one month. 


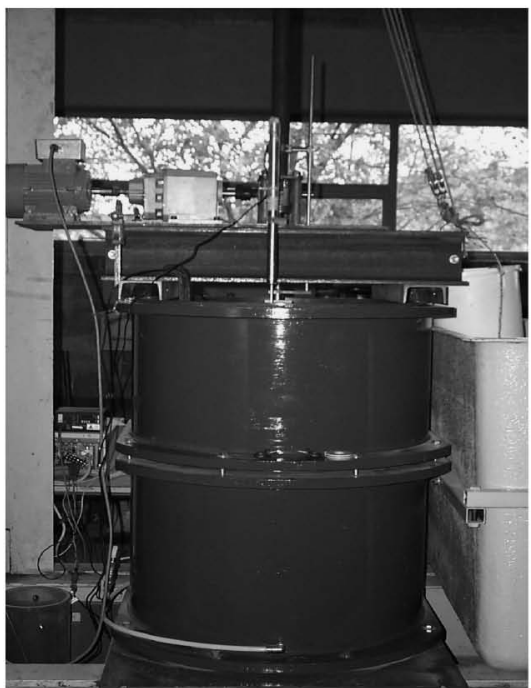

(a) Photograph

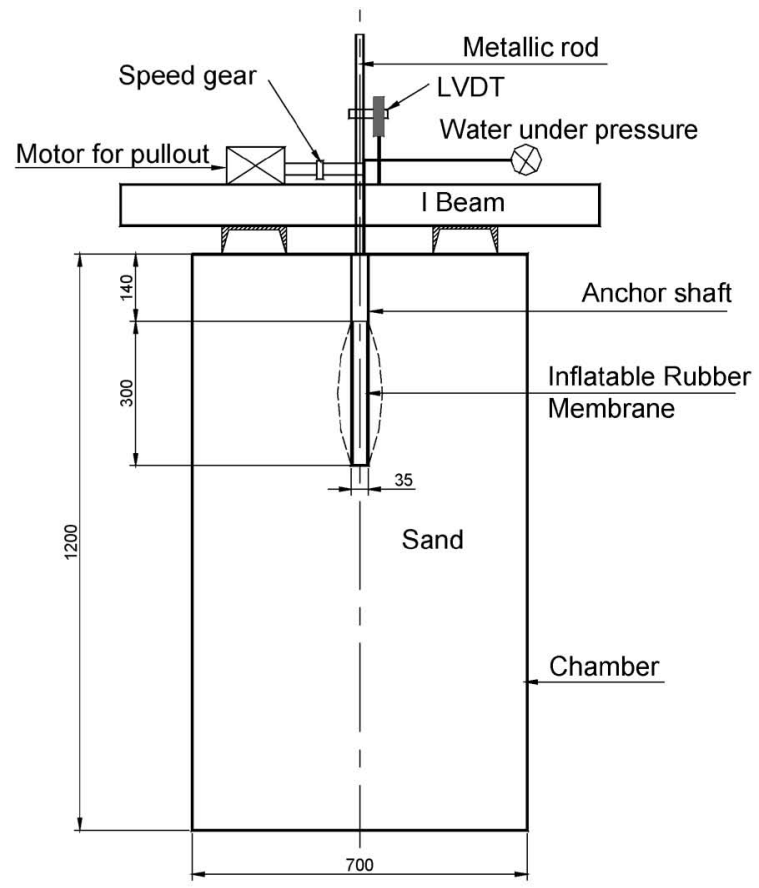

(b) Equipment schematic (Unit: mm)

Fig. 1. Model test chamber (from Newson et al., 2003)

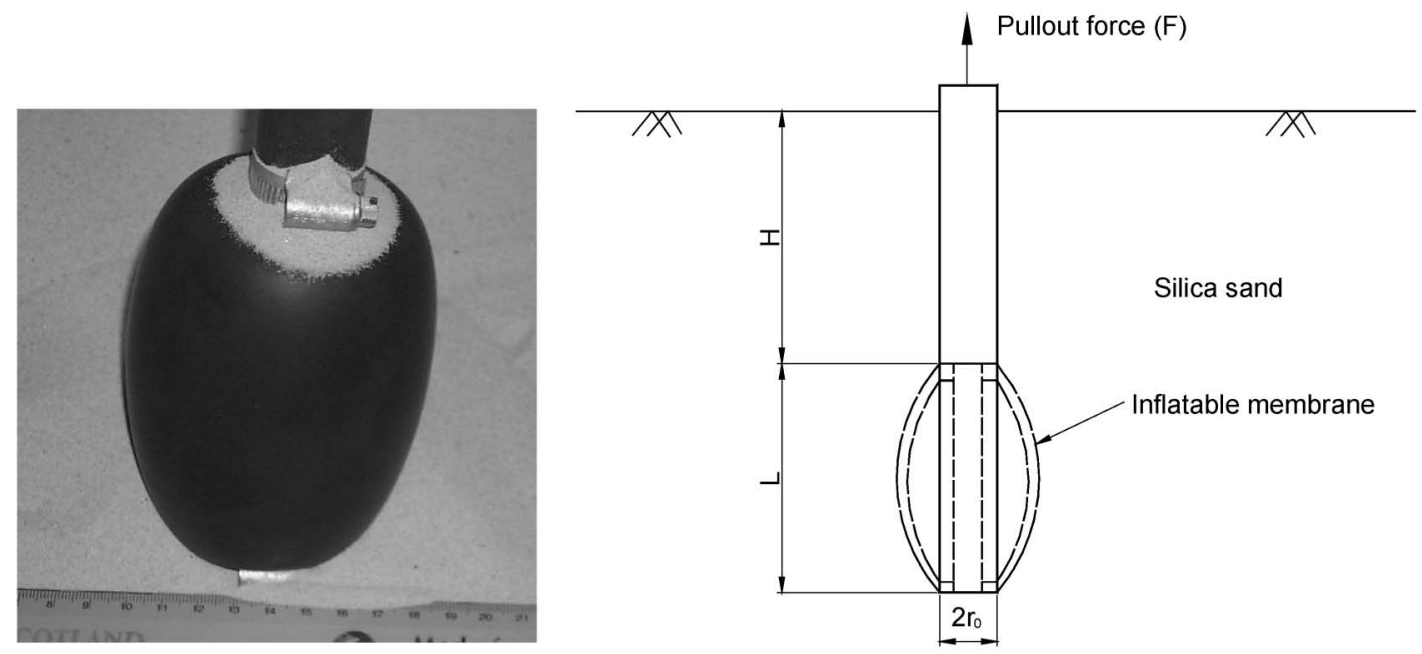

(a) Inflated membrane(unconstrained)

(b) Geometry

Fig. 2. Anchor details

and output, and a pressure transducer to measure the inflation pressure. For some of the tests, a motor with an RS232 interface was added to permit computer control of one of the pumps.

The inflatable anchor comprised a hollow steel anchor rod with two layers of $1.5 \mathrm{~mm}$ thick rubber tubing fixed to the rod using pipe clamps. The anchor is shown in Fig. 2. Tests were done using two different outer membranes: (i) one with sand glued to the membrane to improve its interface strength, and (ii) an untreated rubber membrane in contact with the sand.

\section{Materials and Properties}

Congleton silica sand was used for each test. This sand, which was studied by Gallacher (2000), has a uniform gradation with $D_{50}=0.3 \mathrm{~mm}$, and a specific gravity, $G_{\mathrm{s}}$, of 2.65. The constant volume friction angle is $32^{\circ}$ for densities varying from $1.52 \mathrm{t} / \mathrm{m}^{3}$ to $1.79 \mathrm{t} / \mathrm{m}^{3}$. In addition, interface strength testing was also performed by Gallacher (2000) using a direct shear apparatus for membrane-to-sand interfaces both with and without sand bonded to the membrane. The engineering properties of Congleton sand and the various interface properties are 
summarized in Table 1.

\section{Test Sequence}

Each pullout test comprised filling the test chamber with Congleton sand. Sand beds were constructed by air pluviation using a spot-pouring container at a controlled rate and a fixed height from the soil surface. Higher sand densities were achieved by layered compaction and the inplace density was measured by small density 'pots' (Ueno, 1998). The inflatable anchor was embedded in the sand during sand placement. Consequently, the influence of anchor installation on factors such as soil stiffness and stress state has been neglected; although as detailed below the inflation pressures are very high and thought to dominate any disturbance effects. After filling the test chamber, the reaction beam was bolted to the test chamber (see Fig. 1), the screw jack was mounted to the reac-

Table 1. The engineering properties of Congleton sand and sandmembrane interface (from Gallacher, 2000)

\begin{tabular}{|c|c|}
\hline \multicolumn{2}{|c|}{ Sand Properties } \\
\hline Void ratio $(e)$ & Density $\rho\left(\mathrm{t} / \mathrm{m}^{3}\right)$ \\
\hline 0.48 (min.) & 1.79 (max.) \\
\hline 0.75 (max.) & 1.52 (min.) \\
\hline \multicolumn{2}{|c|}{ Interface Properties } \\
\hline Interface & Friction Angle \\
\hline Rubber/rubber & $19.1^{\circ}$ \\
\hline Sand/rubber & $26.5^{\circ}$ \\
\hline Sand/Roughened membrane & $34^{\circ}$ \\
\hline
\end{tabular}

Table 2. Summary of the conducted tests

\begin{tabular}{ccl}
\hline $\begin{array}{c}\text { Series } \\
\text { No. }\end{array}$ & $\begin{array}{c}\text { Test } \\
\text { No. }\end{array}$ & \multicolumn{1}{c}{ Parameters Varied } \\
\hline A & $1-3$ & Anchor length $(L)$ varied from 100 to $300 \mathrm{~mm}$ \\
B & $4-6$ & Inflation pressure varied from $(P) 80 \mathrm{kPa}$ to $200 \mathrm{kPa}$ \\
C & $7-9$ & Density of sand $(\rho)$ varied \\
D & $10-11$ & Surface roughness of membrane varied \\
\hline
\end{tabular}

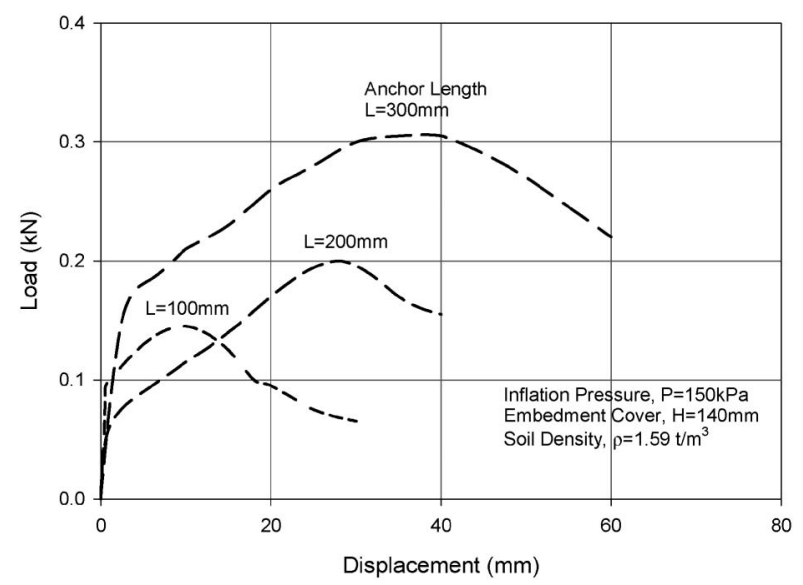

Fig. 3. Typical pullout load-displacement response for inflatable anchors in sand tion beam and connected to the drive motor, the load cell was connected to the anchor head and screw jack, and the LVDT was mounted to the reaction beam and set to rest on the top of the anchor. The anchor was subsequently pulled out of the sand using a constant rate of displacement while simultaneously measuring axial load and displacement and maintaining constant anchor inflation pressure. Table 2 summarizes the conducted tests. Figure 3 shows typical pullout force-displacement curves.

\section{NUMERICAL VALIDATIONS}

The finite element program PLAXIS (Brinkgreve et al., 2002) was used to numerically simulate each of the inflatable anchor tests to evaluate the main factors affecting the pullout response. For this purpose, the ideal model would be one that reproduced the exact experimental sequence. As such, the FE model was formulated such that it accounted for the elastic behaviour of the membrane, cavity expansion of the membrane in the sand and pullout of the inflated anchor. The following is a detailed description of the model and its verification.

\section{Single Membrane Model}

The anchor membrane was modeled as a linear elastic material even though elastomers are known to exhibit nonlinear elastic response. Such an idealization was considered to be adequate given the limited strain-range that the confined membrane underwent during each test and since emphasis was placed on predicting the limit capacity of each anchor. An unconstrained inflation test was performed on the rubber membrane to deduce its elastic properties. The results of this test are shown in Fig. 4(a). Figure 4(b) shows the axisymmetric FE model used to simulate the unconstrained test.

The FE model for unconstrained inflation comprised a membrane of height $300 \mathrm{~mm}$ and thickness $t=3 \mathrm{~mm}$ corresponding to the exact geometry of the anchor membrane. The membrane was discretized using 15-noded linear strain triangles as shown in Fig. 4(b). Rigid fixed boundary conditions were adopted at both ends of the membrane and expansion of the membrane was simulat-

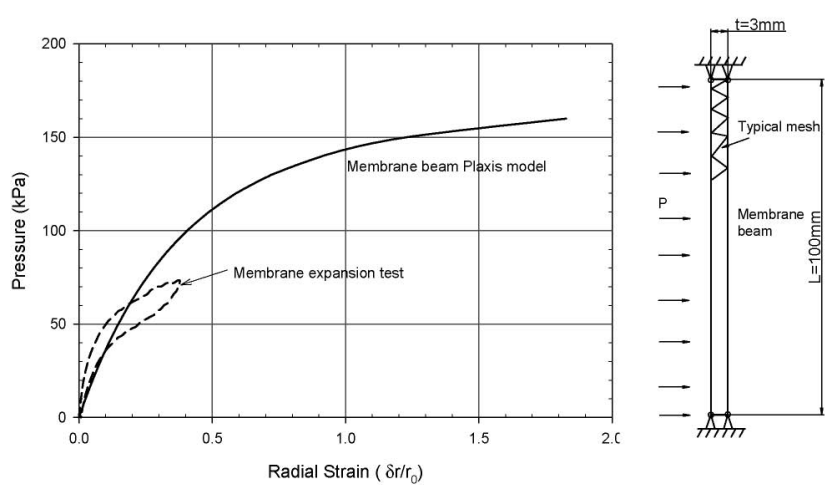

(a) Experimental versus computed anchor response.

(b) FE Geometry

Fig. 4. Calculated and measured unconstrained membrane expansion 
ed by imposing a uniform horizontal pressure on the inside of the membrane that was increased from 0 to 200 $\mathrm{kPa}$ in 40 steps. An approximate geometrically non-linear analysis was done using mesh updating.

The calculated relationship between inflation pressure $(P)$ and radial expansion $\left(\delta \mathrm{r} / r_{0}\right)$ was investigated and it is compared with the measured behaviour in Fig. 4(a). The nonlinear response of the rubber membrane is evident from the laboratory results presented in Fig. 4(a). However, there is reasonable agreement between the calculated and measured radial expansion versus inflation pressure for radial expansion $\left(\delta \mathrm{r} / r_{0}\right)$ up to $30 \%$ and membrane properties of $E=1500 \mathrm{kPa}$ and $v=0.35$ (see Fig. 4(a)). Consequently, these properties were adopted in subsequent finite element analyses. It should be noted that although the radial expansion was in the order of 40 $\%$ for the unconstrained membrane tests, the radial expansion rarely exceeded $30 \%$ during the constrained cavity expansion that occurred during the inflation phase of each pullout test.

\section{Cavity Expansion in Sand}

Cavity expansion of the inflatable membrane in sand, similar to that of a pressuremeter test (Hughes et al., 1977), was experimentally measured and then modeled using PLAXIS. This was done to gain confidence in the computational model and to obtain elastic properties for the sand used in the anchor pullout tests. Figure 5 shows the FE model geometry and Fig. 6 compares experimental and calculated (PLAXIS) results with the $\mathrm{Yu}$ and Houlsby (1991) cavity expansion solution for dilatant soils.

Referring first to Fig. 5, the FE model geometry took into account the axisymmetric geometry. In order to maintain an isotropic initial stress state identical to that assumed in the cavity expansion theory (Yu and Houlsby, 1991), the overburden pressure and horizontal ground pressure at rest were simulated by applying a uniform pressure of $4.35 \mathrm{kPa}$, along lines $\mathrm{A}-\mathrm{B}$ and $\mathrm{B}-\mathrm{C}-\mathrm{D}$ of the FE model. This pressure corresponds to the overburden pressure at the midpoint of the inflatable portion of the anchor during the constrained anchor inflation test. The anchor inflation was simulated by incrementally applying a uniform normal stress along boundary EF in Fig. 5 in 15 steps. An elastic perfectly plastic constitutive model based on the Mohr Coulomb failure criterion was adopted for the sand material assuming a unit weight $\gamma^{\prime}$ of zero. Strength parameters of $\phi^{\prime}=32^{\circ}, \psi^{\prime}=0^{\circ}$ and $c^{\prime}=$ $0.5 \mathrm{kPa}$ were adopted in the analysis for sand, which corresponds to the constant volume parameters of Congle- ton sand obtained from laboratory direct shear tests. The elastic properties of the sand were adjusted in the FE analysis to match the measured pressure versus volume change response of the anchor. Table 3 summarizes the material properties adopted in the FE analysis.

To obtain a FE solution to the constrained cavity expansion, an approach similar to that described in $\mathrm{Yu}$ and Houlsby (1991) was used. Interface elements were introduced between the vertical anchor shaft-to-sand (A-F) interface and membrane-to-sand $(\mathrm{E}-\mathrm{F})$ interface and a horizontal rigid perfectly plastic interface was introduced in the sand layer at the top of the anchor (see F-C in Fig. 5). Although the interface F-C does not physically exist, it is required in the FE mesh (e.g., see Schanz et al., 1999; Brinkgreve et al., 2002) to improve numerical stability by eliminating the local stress concentration that occurs at point $\mathrm{F}$ due to the sudden change in boundary constraint

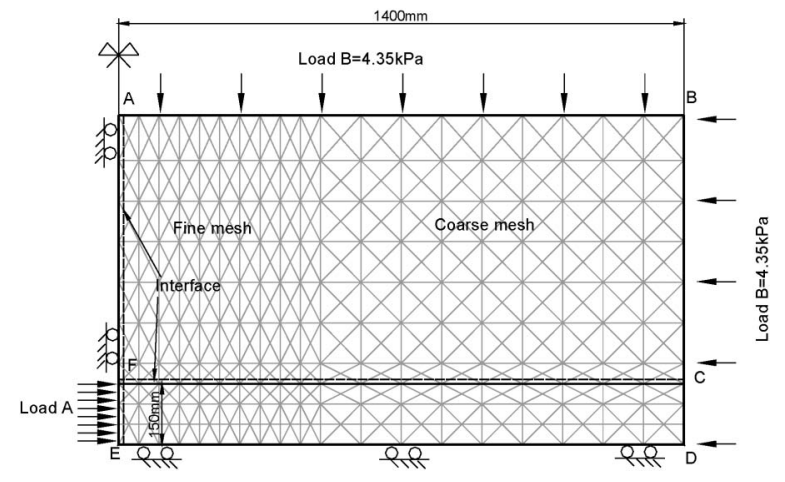

Fig. 5. FE model for cavity expansion in sand

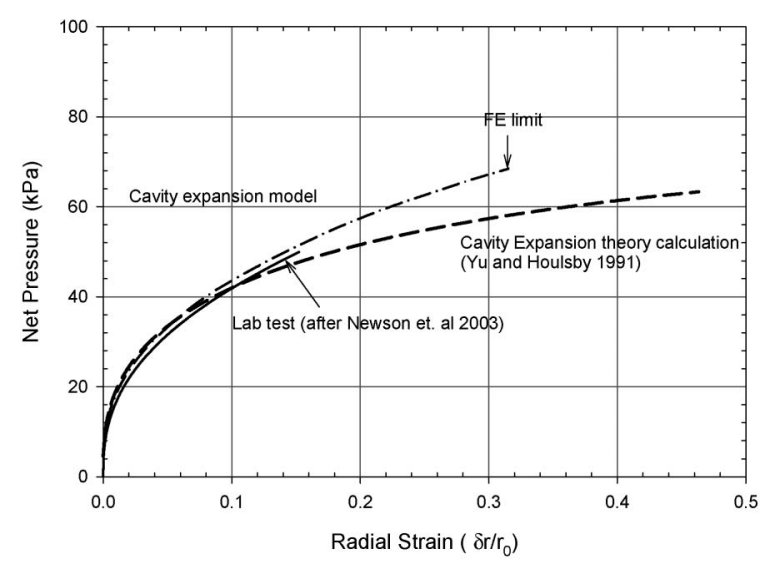

Fig. 6. Comparison of theoretical (Yu and Houlsby, 1991), calculated (FE Method) and measured cavity expansion behavior in sand

Table 3. Summary of the properties of the interfaces for FE model

\begin{tabular}{cccccccc}
\hline & & \multicolumn{3}{c}{ Parameters } \\
\cline { 3 - 7 } Interface & Model & $\begin{array}{c}\gamma^{\prime} \\
\left(\mathrm{kN} / \mathrm{m}^{3}\right)\end{array}$ & $\begin{array}{c}E_{\text {ref }} \\
(\mathrm{kPa})\end{array}$ & $v$ & $\begin{array}{c}c^{\prime} \\
(\mathrm{kPa})\end{array}$ & $\begin{array}{c}\phi^{\prime} \\
(\text { Degree) }\end{array}$ & $\begin{array}{c}\psi^{\prime} \\
(\text { Degree) }\end{array}$ \\
\hline $\mathrm{AF} / \mathrm{FE} / \mathrm{FC}$ & Mohr-Coulomb & 0 & 6000 & 0.35 & 0.5 & $32^{\circ}$ & $0^{\circ}$ \\
the interfaces (Degree)
\end{tabular}


from free along E-F to fixed along F-A. The strength perameters of interface $\mathrm{F}-\mathrm{C}$ were identical to that of the soil. The full set of interface parameters used in the analysis is summarized in Table 3. Referring to Fig. 5, it is noted that the FE mesh was locally very fine adjacent to the anchor and becoming coarser with distance from the anchor.

Calculated and measured net pressure versus radial expansion, $\delta \mathrm{r} / r_{0}$, is compared with cavity expansion theory in Fig. 6. In this figure, the net pressure is the anchor inflation pressure corrected for membrane effects (e.g., subtracting contributions due to the membrane, see Fig. 4(a)). From Fig. 6, it can be seen that a limit pressure $\left(P_{\mathrm{L}}\right)$ of $70 \mathrm{kPa}$ was obtained from the $\mathrm{FE}$ analysis at $\delta \mathrm{r} / r_{0}$ of $32 \%$. A limit pressure of $64 \mathrm{kPa}$ was obtained from cavity expansion theory ( $\mathrm{Yu}$ and Houlsby, 1991) at a maximum $\delta \mathrm{r} / r_{0}$ of about $46 \%$. The limit pressures from both FE analysis and cavity expansion theory are comparable and they agree well with the actual measured behaviour of the anchor during constrained cavity expansion. The analysis and discussions presented above serve to demonstrate the adequacy of the FE model used in the study. From Fig. 6, it can be seen that the FE analysis and measured response are within $10 \%$ for net pressures up to about $50 \mathrm{kPa}$, corresponding to an internal inflation pressure in the order of $100 \mathrm{kPa}$.

\section{FE MODEL FOR INFLATABLE ANCHOR IN SAND}

\section{Model Configuration and Materials Properties}

Figure 7 shows the FE model used to investigate the inflatable anchor behaviour and Table 4 summarizes the material properties. The FE model consists of the anchor shaft, rubber membrane and sand around the anchor. Axisymmetric geometry was modeled using 15-noded cubic strain elements to discretize the sand and rubber membrane. Each finite element analysis comprised: (i) first setting up the initial stresses in the sand; (ii) simulating inflation of the membrane inducing cavity expansion; and (iii) finally simulating the pullout response. The model configuration, material properties and other details of the FE calculations are described below. Finite element discretization of the membrane and soil did not deviate sig- nificantly from that described in the verification problems discussed above.

\section{Anchor Shaft}

The $35 \mathrm{~mm}$ diameter anchor shaft was modeled using continuum elements assuming linear-elastic material (steel) behaviour. The Young's modulus and Poisson's ratio were taken as $200 \mathrm{MPa}$ and 0.3 , respectively. The cover depth $(H)$ and the length of the inflatable anchor $(L)$ were variable corresponding to each of the test cases (see Table 2). Figure 7 shows the geometry corresponding to $H=140 \mathrm{~mm}$ and $L=300 \mathrm{~mm}$.

\section{Membrane}

Based on the unconstrained membrane tests described above, the membrane was modeled as a linear-elastic material with a thickness of $t=3 \mathrm{~mm}$, and Young's modulus of $1500 \mathrm{kPa}$ and Poisson's ratio of 0.35 . The length of the membrane corresponds to the length of the inflatable anchor for the specific test considered (Fig. 7).

\section{Sand Layers}

The sand was modeled as an elastic-perfectly plastic material with failure governed by the Mohr Coulomb
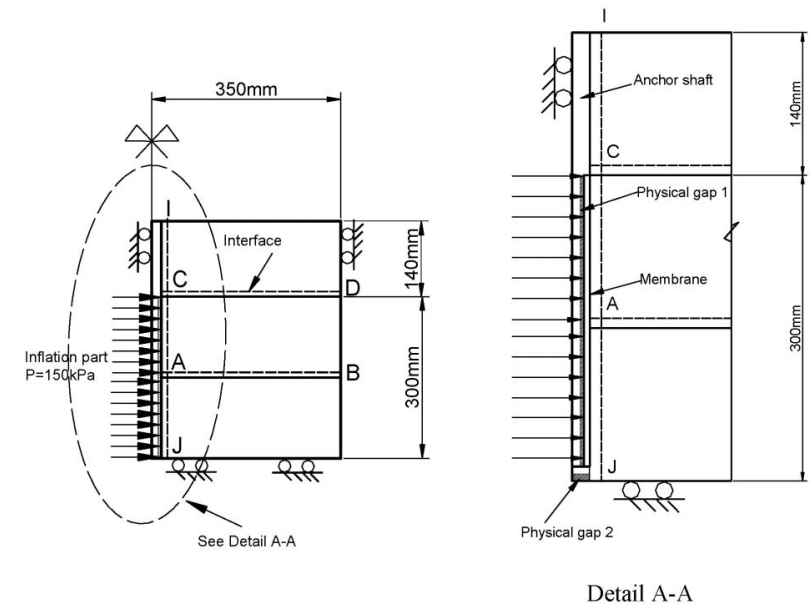

Fig. 7. Geometry of the FE model for embedded inflatable anchor of length $L=300 \mathrm{~mm}$

Table 4. Summary of the parameters used in the FE analysis

\begin{tabular}{|c|c|c|c|c|}
\hline Parameter & $\begin{array}{c}\text { Anchor Shaft } \\
\text { (Steel) }\end{array}$ & Membrane & Sand & Unit \\
\hline Material model & Linear Elastic & Linear Elastic & Mohr-Coulomb & - \\
\hline Behavior & Non porous & Non porous & Drained & - \\
\hline Unit weight, $\gamma^{\prime}$ & 24 & 15.6 & $14.9 \sim 15.6$ & $\mathrm{kN} / \mathrm{m}^{3}$ \\
\hline Young's modulus, $E_{\text {ref }}$ & $2 \times 10^{8}$ & 1500 & 6000 & $\mathrm{kN} / \mathrm{m}^{2}$ \\
\hline Poisson's ratio, $v$ & 0.3 & 0.35 & 0.35 & - \\
\hline Cohesion, $c^{\prime}$ & - & - & 0.5 & $\mathrm{kN} / \mathrm{m}^{2}$ \\
\hline Friction angle, $\phi^{\prime}$ & - & - & $32^{\circ} \sim 36^{\circ}$ & Degree \\
\hline Dilatancy angle, $\Psi^{\prime}$ & - & - & $0 \sim 3.2^{\circ}$ & Degree \\
\hline $\begin{array}{l}\text { Interface strength, } \delta \\
\text { (for each material in contact with sand) }\end{array}$ & $3 \sim 4^{\circ}$ & $\begin{array}{c}26.5 \sim 34^{\circ}\left(\text { For } L_{\mathrm{e}}\right) \\
0.5^{\circ}\left(\text { Below } L_{\mathrm{e}}\right)^{\mathrm{a}}\end{array}$ & $\begin{array}{l}\text { Equal to } \phi^{\prime} \\
\text { for A-B, C-D }\end{array}$ & Degree \\
\hline
\end{tabular}

\footnotetext{
a $L_{\mathrm{e}}=\alpha L$ effective length and $\alpha$ is in the range of $0 \sim 1.0$
} 
failure criterion. The sand properties are listed in Table 4.

The sand was modeled to the bottom of the anchor only based on studies that have shown the soil below the anchor base has a negligible effect on the anchor behaviour for drained conditions due to breakaway (e.g., Kanakapura et al., 1994). From back-calculation of the constrained cavity expansion test described above, the Young's modulus and Poisson's ratio of the sand were $6000 \mathrm{kPa}$ and 0.35 , respectively. The effective friction angle was varied between $32^{\circ}$ and $36^{\circ}$ depending on the sand density and taking into account the results of laboratory direct shear tests on the Congleton sand (Gallacher, 2000). For loose sand $\left(\gamma^{\prime}=14.9 \mathrm{kN} / \mathrm{m}^{3}\right)$, the constant volume friction angle of $\phi_{\mathrm{cv}}^{\prime}=32^{\circ}$ and $\psi^{\prime}=0^{\circ}$ were used in the FE model. For the more dense sand, peak friction angles, $\phi_{\mathrm{p}}^{\prime}$, of $34^{\circ}$ and $36^{\circ}$ were used for sands with $\gamma^{\prime}=15.2 \mathrm{kN} / \mathrm{m}^{3}$ and $\gamma^{\prime}=15.6 \mathrm{kN} / \mathrm{m}^{3}$, respectively, and the corresponding dilation angle $\psi^{\prime}$ was deduced using the relationship $\psi^{\prime}=0.8\left(\phi_{\mathrm{p}}^{\prime}-\phi_{\mathrm{cv}}^{\prime}\right)$ from Bolton (1986). The coefficient of lateral earth pressure at rest was assumed to be $K_{0}^{\prime}=0.5$ to calculate the initial stresses.

\section{Effective Length of the Inflatable Anchor $\left(L_{e}\right)$}

The main purpose of the FE analyses reported in this paper was to interpret the ultimate pullout load (pullout capacity) of the inflatable anchors. However, during the initial back analysis of the anchor tests, it was found that the pullout capacity could not be interpreted for all anchors using an effective friction angle, $\phi^{\prime}$, for the sand that agreed with laboratory direct shear tests (Gallacher, 2000). In addition, in many cases it was necessary to vary $\phi^{\prime}$ for anchors of different length but installed in sand with the same density. As a result, the test results were reinterpreted by modeling: (i) an upper effective zone, denoted $L_{\mathrm{e}}$ for effective length, with interface properties corresponding to those measured for the sand-to-rubber interface and (ii) a lower zone, which was assumed to be ineffective and assigned a very small interface friction angle to limit the shear strength to approximately zero.

Thus, it was assumed that each anchor has an effective length $L_{\mathrm{e}}$ that is less than the physical length of the anchor and the FE analysis was undertaken to back calculate $L_{\mathrm{e}}$ for each anchor using properties that were consistent with Congleton sand and its corresponding state. Additionally, it is noted that the concept of effective length is very common in the analysis of anchors and piles during pullout (see Wald et al., 2008; Degil', 1991; Indraranta, 1991; Iskander et al., 2002; Bhattacharya et al., 2003; Ahmad et al., 2005; Nihar et al., 2006). In the following sections, the effective length $\left(L_{\mathrm{e}}\right)$ is often represented by $\alpha L$ in figures, where $\alpha$ is a coefficient varying from 0 to 1.0 , and $L$ is the anchor (membrane) length.

\section{Interface in Sand}

Two horizontal interfaces denoted A-B and C-D in Fig. 7 were introduced to solve the cavity expansion or inflation stage of each test. These interfaces were rigid per- fectly plastic interfaces with shear strength parameters identical to that adopted for the sand (see Table 4).

Three vertical interfaces were introduced along the length of each anchor (I-J) as shown in Fig. 7. In PLAXIS, the friction angle of the interface, $\delta$, is defined by the equation $\tan \delta=R_{\text {int }} \tan \phi^{\prime}$, where $R_{\text {int }}$ is a reduction factor and $\phi^{\prime}$ is the effective friction angle of soil adjacent to the interface. Based on the laboratory results summarized in Table 1, the friction angles of the sand-to-sand and sand-to-rubber interfaces are $34^{\circ}$ and $26.5^{\circ}$, respectively. The corresponding reduction factors used in the analysis were $R_{\text {int }}=0.1\left(\delta=3-4^{\circ}\right)$ on the anchor shaft-to-soil interface, $R_{\text {int }}=0.74-1.0\left(\delta=26.5-34^{\circ}\right)$ on the membrane-tosoil interface in the effective length zone $\left(L_{\mathrm{e}}\right)$, and $R_{\text {int }}=$ $0.01\left(\delta=0.5^{\circ}\right)$ on the membrane-to-soil interface below the effective length zone. A small friction angle was required below the effective zone to ensure numerical stability (see also Kanakapura et al., 1994). The material parameters used in the FE analysis are summarized in Table 5.

\section{Boundary Conditions}

The lateral FE boundary extends $350 \mathrm{~mm}$ from the anchor axis, which is 10 times the anchor diameter and identical to the dimensions of the test chamber. Fixed $x$ displacement and free $y$-displacement boundaries were adopted on both sides of the model, and fixed $y$-displacement and free $x$-displacement boundaries were given to the base if the sand layer (see Fig. 7).

\section{Solution Sequence}

The FE solution sequence involved three stages. (i) First, the initial geostatic stresses in the sand were established assuming $K_{0}^{\prime}=0.5$. (ii) Then, inflation of the anchor (cavity expansion) was simulated numerically using mesh updating. Thus, the cavity expansion solution involved approximate geometric non-linearity. (iii) Finally, anchor pullout was simulated but without mesh updating as discussed below.

For the inflation stage, a physical gap was introduced in the FE mesh between the anchor shaft and the membrane elements (see Physical gap 1 in Fig. 7). This physical gap was required to apply the inflation pressures (see Fig. 7), which were specified as a uniform stress (Load A) incrementally from 0 to the inflation pressure reported during each model test (in $\mathrm{kPa}$ ) along the inner surface of the membrane.

After simulating the anchor expansion, pullout was simulated by prescribed displacements at the top of the anchor. A second physical gap (Physical gap 2 in Fig. 7) was introduced in the model at the bottom of the anchor to avoid tension along this interface. Unlike the anchor inflation stage, the pullout stage was analyzed without mesh updating because the mesh updating caused numerical instability during the pullout simulations. The source of instability is thought to arise from the use of interface elements along line $\mathrm{C}-\mathrm{J}$ in Fig. 7, which can tolerate only a limited amount of shear displacement during mesh updating before becoming ill-conditioned (e.g., the length 
Table 5. Summary of the lab tests (Newson et al., 2003) and the corresponding FE analyses

\begin{tabular}{|c|c|c|c|c|c|c|c|c|c|c|c|c|c|}
\hline \multirow{2}{*}{ Parameter } & \multicolumn{12}{|c|}{ Lab Test/FE Analysis } & \multirow{2}{*}{ Unit } \\
\hline & & $1^{b} / A^{c}$ & $2 / \mathrm{B}$ & $3 / \mathrm{C}$ & $4 / \mathrm{D}$ & $5 / \mathrm{E}$ & $6 / \mathrm{F}$ & $7 / \mathrm{G}$ & $8 / \mathrm{H}$ & $9 / \mathrm{I}$ & $10 / \mathrm{J}$ & $11 / \mathrm{K}$ & \\
\hline Anchor length $^{1}$ & $L$ & 100 & 200 & 300 & 300 & 300 & 300 & 300 & 300 & 300 & 300 & 300 & $\mathrm{~mm}$ \\
\hline Embedment depth ${ }^{1}$ & $H$ & 140 & 140 & 140 & 140 & 140 & 140 & 140 & 140 & 140 & 140 & 140 & $\mathrm{~mm}$ \\
\hline Inflation pressure ${ }^{1}$ & $P$ & 150 & 150 & 150 & 80 & 150 & 200 & 150 & 150 & 150 & 150 & 150 & $\mathrm{kPa}$ \\
\hline Unit weight ${ }^{1}$ & $\gamma^{\prime}$ & 15.6 & 15.6 & 15.6 & 14.9 & 14.9 & 14.9 & 14.9 & 15.2 & 15.6 & 14.9 & 14.9 & $\mathrm{kN} / \mathrm{m}^{3}$ \\
\hline Effective Length coefficient ${ }^{3}$ & $\alpha$ & 0.9 & 0.5 & 0.45 & 0.15 & 0.45 & 0.45 & 0.45 & 0.45 & 0.45 & 0.45 & 0.45 & \\
\hline Young's modulus ${ }^{1}$ & $E_{\text {ref }}$ & 6 & 6 & 6 & 6 & 6 & 6 & 6 & 6 & 6 & 6 & 6 & $\mathrm{MN} / \mathrm{m}^{2}$ \\
\hline Poisson's ratio ${ }^{2}$ & $v$ & 0.35 & 0.35 & 0.35 & 0.35 & 0.35 & 0.35 & 0.35 & 0.35 & 0.35 & 0.35 & 0.35 & \\
\hline Cohesion $^{1}$ & $c^{\prime}$ & 0.5 & 0.5 & 0.5 & 0.5 & 0.5 & 0.5 & 0.5 & 0.5 & 0.5 & 0.5 & 0.5 & $\mathrm{kPa}$ \\
\hline Friction angle ${ }^{1,4}$ & $\phi^{\prime}$ & 36 & 36 & 36 & 32 & 32 & 32 & 32 & 34 & 36 & 32 & 32 & Degree \\
\hline Dilatancy angle $e^{2,5}$ & $\psi^{\prime}$ & 3.2 & 3.2 & 3.2 & 0 & 0 & 0 & 0 & 1.6 & 3.2 & 0 & 0 & Degree \\
\hline Anchor shaft-soil Interface ${ }^{2}$ & $\delta$ & 4 & 4 & 4 & 3.6 & 3.6 & 3.6 & 3.6 & 3.3 & 3.5 & 3 & 3 & Degree \\
\hline Membrane-soil interface ${ }^{1}\left(L_{\mathrm{e}}\right.$ Part) & $\delta$ & 26.5 & 26.5 & 26.5 & 26.5 & 26.5 & 26.5 & 26.5 & 26.5 & 26.5 & 26.5 & 34 & Degree \\
\hline Membrane-soil interface ${ }^{3}$ (below $L_{\mathrm{e}}$ ) & $\delta$ & 0.5 & 0.5 & 0.5 & 0.5 & 0.5 & 0.5 & 0.5 & 0.5 & 0.5 & 0.5 & 0.5 & Degree \\
\hline Soil-to-soil interface ${ }^{1}$ & $\delta$ & 36 & 36 & 36 & 32 & 32 & 32 & 32 & 34 & 36 & 32 & 32 & Degree \\
\hline
\end{tabular}

Notes: ${ }^{\mathrm{b}}$ The sequence number $1 \sim 11$ denotes the lab test number (see Figs. $8 \sim 11$ )

${ }^{\mathrm{c}}$ The sequence letter $\mathrm{A} \sim \mathrm{K}$ denotes the $\mathrm{FE}$ analysis case corresponding to the lab tests (see Figs. 8 11)

${ }^{1}$ Parameters that were measured

${ }^{2}$ Parameters that were estimated

${ }^{3}$ Parameters that were deduced or back-calculated

${ }^{4} \phi_{\mathrm{p}}^{\prime}$ was interpolated from $\phi_{\mathrm{cv}}^{\prime}$ and $\phi_{\mathrm{p}}^{\prime}$ data in Gallacher (2000)

${ }^{5} \psi^{\prime}$ was estimated from Bolton (1986)

of interface elements on boundary $\mathrm{C}-\mathrm{J}$ was only $5 \mathrm{~mm}$ ). This limitation in the analysis will be discussed below after presentation of the results.

\section{RESULTS}

In this section, FE calculations are compared with the measured behaviour of model anchors during the pullout tests. For the finite element analyses, the variables considered were the anchor length $(L)$, inflation pressure $(P)$, density of the soil $(\rho)$, and membrane surface roughness. For all cases, the primary variable was the effective length, which was deduced by varying $L_{\mathrm{e}}$ to obtain agreement between the calculated and measured behaviour.

\section{Effect of Anchor Length (L)}

Figure 8 compares the calculated and measured pullout behaviour of $100 \mathrm{~mm}, 200 \mathrm{~mm}$ and $300 \mathrm{~mm}$ long anchors with $140 \mathrm{~mm}$ embedment depth $(H)$. For these tests, the inflation pressure $(P)$ was $150 \mathrm{kPa}$ and the density of the sand $(\rho)$ was essentially the same, $1.59 \mathrm{t} / \mathrm{m}^{3}$ for each test. To obtain the calculated behaviour, the effective anchor length $\left(L_{\mathrm{e}}\right)$ was set at $0.9 L, 0.5 L$ and $0.45 L$ for anchors of length $(L) 100 \mathrm{~mm}, 200 \mathrm{~mm}$ and $300 \mathrm{~mm}$, respectively.

From Fig. 8, it can be seen that the maximum pullout capacity calculated by FE method varies from $0.14 \mathrm{kN}$ to $0.29 \mathrm{kN}$, which agrees well with the lab tests. Such agreement could not be obtained assuming that the full length

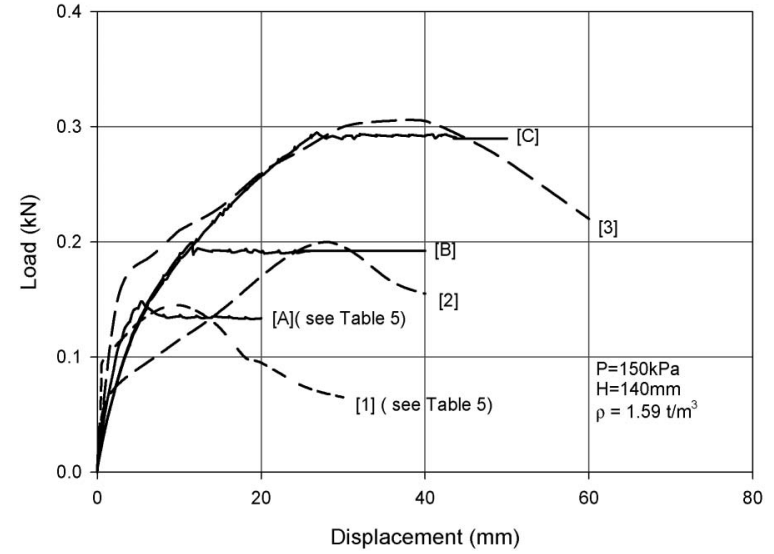

Fig. 8. Comparison of measured and calculated pullout force versus displacement for various anchor lengths $(L)$

of the anchor was effective in resisting the pullout loads (see Newson et al., 2007). Although there is good agreement for the ultimate capacity of the anchors, the displacement mobilized at the peak load is consistently less than that measured in each test. This may be due to distortion of the rubber membrane possibly caused by stress concentrations at the top of the anchor near the membrane-to-shaft connection. In addition, as shown in Fig. 4 , the stress-strain response of the rubber is nonlinear which has not been accounted for in this analysis. 


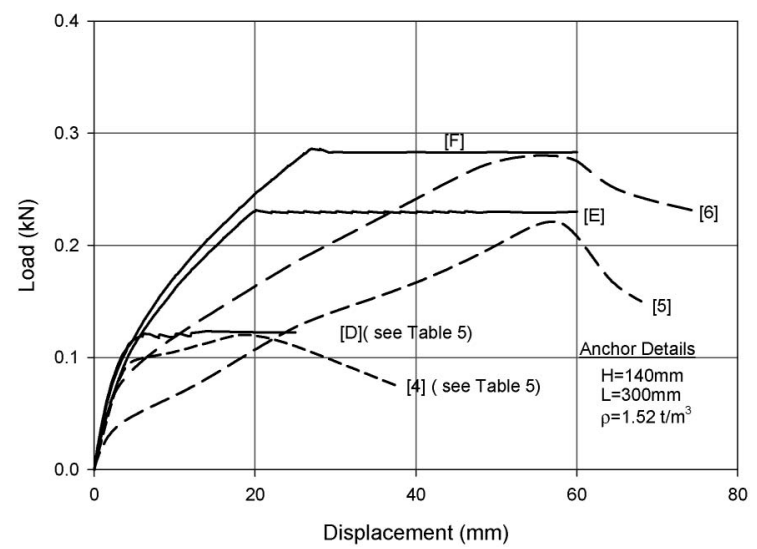

Fig. 9. Comparison of calculated and measured pullout force versus displacement for different inflation pressures $(P)$

\section{Inflation Pressure $(P)$}

Figure 9 shows the effect of varying the inflation pressure on the pullout resistance of the inflatable anchors. For this series of tests, the embedment depth $(H)$ was 140 $\mathrm{mm}$, the anchor length $(L)$ was $300 \mathrm{~mm}$, the soil density $(\rho)$ was $1.52 \mathrm{t} / \mathrm{m}^{3}$, and the inflation pressure $(P)$ was varied from $80 \mathrm{kPa}$ to $200 \mathrm{kPa}$. In order to obtain reasonable agreement between the measured and calculated pullout behaviour, the effective length $\left(L_{\mathrm{e}}\right)$ was $0.15 \mathrm{~L}, 0.45 \mathrm{~L}$ and $0.45 \mathrm{~L}$ for anchors inflated to pressures of $80 \mathrm{kPa}$, $150 \mathrm{kPa}$ and $200 \mathrm{kPa}$ respectively. Consequently, it is inferred on the basis of the actual anchor performance that the effective length is also proportional to the inflation pressure.

From Fig. 9, it can be seen that the calculated peak pullout resistance varies from $0.13 \mathrm{kN}$ for $P=80 \mathrm{kPa}$ to 0.28 $\mathrm{kN}$ for $P=200 \mathrm{kPa}$. The calculated pullout resistance agrees well with the test data. The displacement mobilized at the peak strength is higher for each of the scaled model tests compared with the FE calculations. Again, this may be due to nonlinearity of the rubber membrane and membrane distortions at the upper connection.

\section{Density of Soil $(\rho)$}

Figure 10 shows the effect of soil density on the pullout capacity of the inflatable anchors. For this sequence of tests, the sand density $(\rho)$ was varied from $1.52 \mathrm{t} / \mathrm{m}^{3}$ to $1.59 \mathrm{t} / \mathrm{m}^{3}$. Accordingly, the parameters governing the strength and dilation of the sand, which are summarized in Table 5, were varied slightly according to the density of the sand. For each test and FE simulation, the inflation pressure $(P)$ was $150 \mathrm{kPa}$, the embedment depth $(H)$ was $140 \mathrm{~mm}$ and the anchor length $(L)$ was $300 \mathrm{~mm}$. Given the consistent geometry of these anchors, the effective length $\left(L_{\mathrm{e}}\right)$ was $0.45 L$ for each analysis.

Referring to Fig. 10, it can be seen that the peak pullout resistance from the FE analysis agrees very well with the test results. The calculated displacement mobilized at the peak strength varied from $20 \mathrm{~mm}$ to $26 \mathrm{~mm}$, which is again less than that obtained during the lab tests. As with the other simulations, however, the agreement between

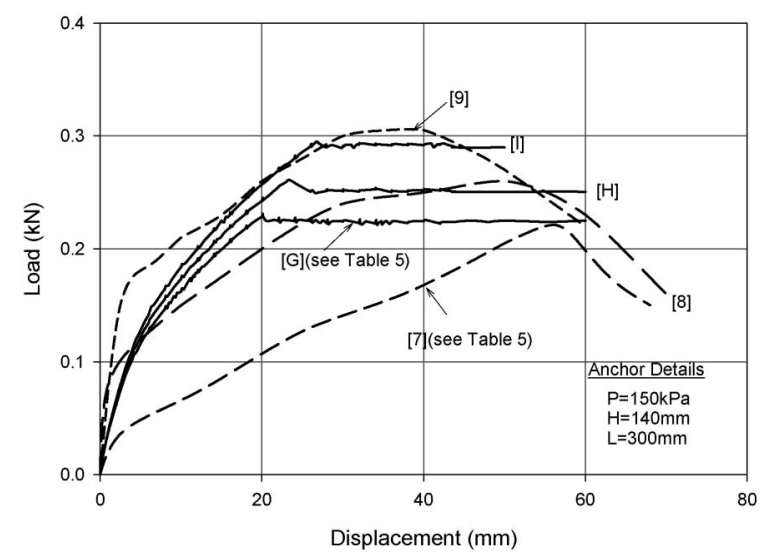

Fig. 10. Comparison of measured and calculated pullout force versus displacement for different sand densities $(\rho)$

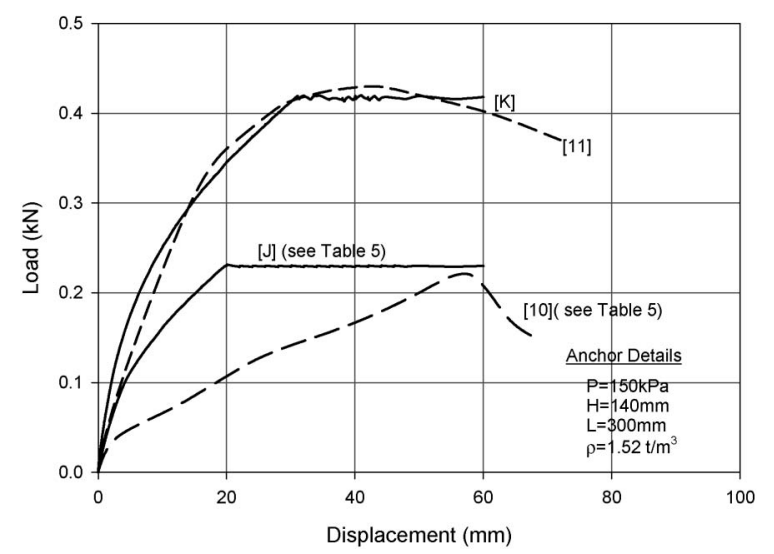

Fig. 11. Comparision of measured and calculated pullout force versus displacement for different membrane surface treatments

calculated and measured peak load is adequate.

\section{Membrane Surface Roughness}

To conclude, variations in the pullout capacity due to variations in the membrane treatment (rubber only versus rubber with sand bonded to it) were investigated and the results are summarized in Fig. 11. For each of these tests, the soil density $(\rho)$ was $1.52 \mathrm{t} / \mathrm{m}^{3}$, the embedment depth $(H)$ was $140 \mathrm{~mm}$, the anchor length $(L)$ was $300 \mathrm{~mm}$ and the inflation pressure $(P)$ was $150 \mathrm{kPa}$. The calculated behaviour in Fig. 11 is based on an effective length $\left(L_{\mathrm{e}}\right)$ of 0.45 for both the untreated and roughened membrane. For the roughened membrane surface, the interface friction angle, $\delta$, was $34^{\circ}$ compared to that of the untreated membrane, $\delta=26.5^{\circ}$ (see Table 1 ).

From Fig. 11, it can be seen that the peak pullout resistance from $\mathrm{FE}$ analyses varies from $0.22 \mathrm{kN}$ to 0.42 $\mathrm{kN}$, which matches the measured peak loads with again discrepancies in the displacement mobilized at the peak pullout load. 


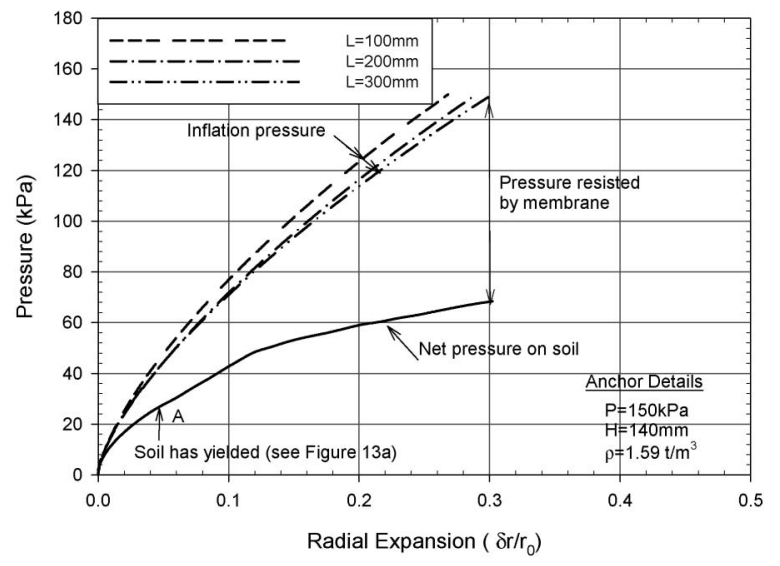

Fig. 12. Calculated pressure versus radial expansion during confined cavity expansion

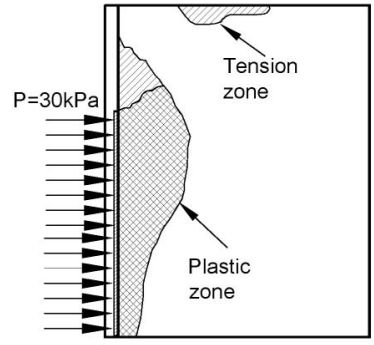

(a) $\mathrm{P}=30 \mathrm{kPa}$

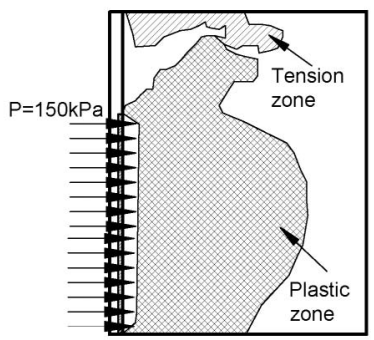

(b) $\mathrm{P}=150 \mathrm{kPa}$
Fig. 13. Calculated plastic zone for $P=30 \mathrm{kPa}$ and $150 \mathrm{kPa}$ during inflation for test $\mathbf{C}$

\section{DISCUSSION}

\section{Anchor Mechanics}

Figure 12 shows the calculated net pressure on the soil and the internal inflation pressure versus radial expansion $\left(\delta \mathrm{r} / r_{0}\right)$ for anchors of length $100 \mathrm{~mm}, 200 \mathrm{~mm}$ and 300 $\mathrm{mm}$, inclusive, for anchor test $\mathrm{C}$. In addition, the net pressure causing full yielding in the soil is denoted by Point $\mathrm{A}$. It is noted that a maximum radial expansion of $30 \%$ was reached at an inflation pressures of $P=150 \mathrm{kPa}$. From Fig. 12, it can be seen that for $P=150 \mathrm{kPa}$ at $\delta \mathrm{r} / r_{0}$ of $30 \%$, the net pressure supported by the sand is about $70 \mathrm{kPa}$ and the difference $(80 \mathrm{kPa})$ was resisted by the membrane. In addition, the soil is well past its yield point as discussed further in reference to Fig. 13 below.

Figure 13 shows the plastic zones after cavity expansion corresponding to inflation pressures of $30 \mathrm{kPa}$ and $150 \mathrm{kPa}$. From Fig. 13, it can be seen that there are extensive zones of plasticity in the soil surrounding the inflated portion of the anchor and that the size and extent of the yield zone increases with inflation pressure from $P=30$ $\mathrm{kPa}$ to $150 \mathrm{kPa}$. As a consequence, the pullout capacity of this type of inflated anchor is strongly influenced by the response of the embedment soil at its limit pressure as shown by Figs. 12 and 13.

Figure 14 shows a typical velocity field and the associated zones of plasticity during pullout for anchor test $\mathrm{C}$ (see Table 5). From Fig. 14(a) (d), it can be seen that both the velocity field and the plastic zones are progressively developed around the upper part of the anchor during pullout, which is above the defined effective length $\left(L_{\mathrm{e}}\right)$. The velocity fields and plastic zones are governed by the effective length assumed in the analyses of the anchors.

Figure 15 shows contours of the shear strain developed in the sand around anchor $\mathrm{C}$ during pullout. It can be seen that, for an anchor head displacement $\delta_{\mathrm{v}}$ of $12.5 \mathrm{~mm}$ corresponding to the displacement ratio $\delta_{\mathrm{v}} / r_{0}$ of 0.7 (see Fig. 15(a)), the maximum shear strain developed around the upper part of the anchor is $19.1 \%$ and it is concentrated within the relatively narrow zone adjacent to the anchor (i.e., along the interface). At an anchor head displacement of $28 \mathrm{~mm}$ reaching the peak pullout load with the displacement ratio $\delta_{v} / r_{0}$ of 1.6 (see Fig. 15(b)), the shear zone begins to propagate toward the soil surface along the boundary of the pullout mechanism depicted in Fig. 14(c).

Figure 16 shows the measured and calculated relationship between the normalized pullout force and the displacement. For this figure, the pullout load $(P)$ was normalized by the peak load ( $\left.P_{\text {peak }}\right)$ during each test. The vertical displacement $\left(\delta_{v}\right)$ was likewise normalized by the displacement at the peak load $\left(\delta_{\text {peak }}\right)$. As expected, a unique normalized curve was obtained from the FE analyses. The normalized FE curve (see Fig. 16) agrees well with the normalized test data, which is likely influenced by variations in the test conditions.

\section{Effective Length}

As noted above, a consistent interpretation of the anchor behavior could only be obtained for all tests by varying the effective length $\left(L_{\mathrm{e}}\right)$ of each anchor. Other interpretations were possible but only if the soil parameters (such as $\phi^{\prime}$ ) were varied significantly outside the range measured in the laboratory for Congleton sand (see Gallacher, 2000; Newson et al., 2007). However, the effective length concept permitted the use of material parameters that were consistent from test to test and that agreed with the measured parameters.

Figure 17 illustrates a hypothesis that could explain the mobilization of an effective anchor length for inflatable anchors. After cavity expansion, the anchor shape is approximately cylindrical based on the FE results but with a larger diameter at the top and smaller diameter toward the bottom. The solid line in Fig. 17 denotes the anchor shape after inflation. During pullout, however, it is hypothesized that the anchor deforms into a 'tear drop' shape due to the flexible nature of the membrane. In this case, the lower part of the membrane-soil interface is less kinematically favorable for the development of shear bands and may not even slip relative to the soil. This mechanism would tend to reduce the contribution of the lower portions of the membrane toward the pullout capacity.

Lastly, it can be shown that the pullout capacity of an inflatable anchor is dependent on the following indepen- 


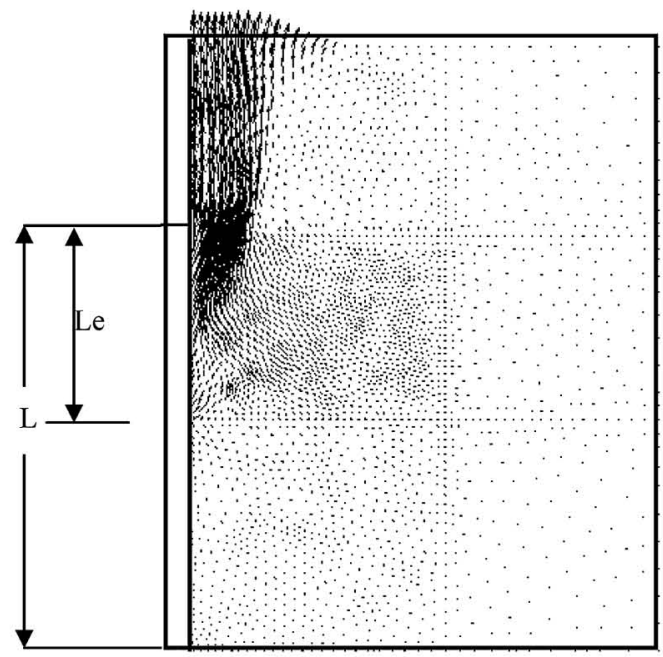

(a) Velocity field at a pullout displacement ratio $\delta_{v} / r_{0}=0.7$

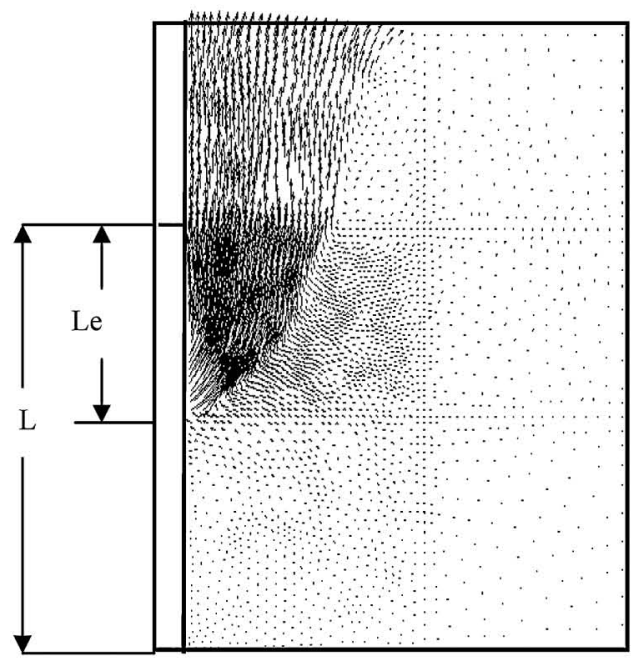

(c) Velocity field at a pullout displacement ratio $\delta_{v} / r_{0}=1.6$ (Failure)

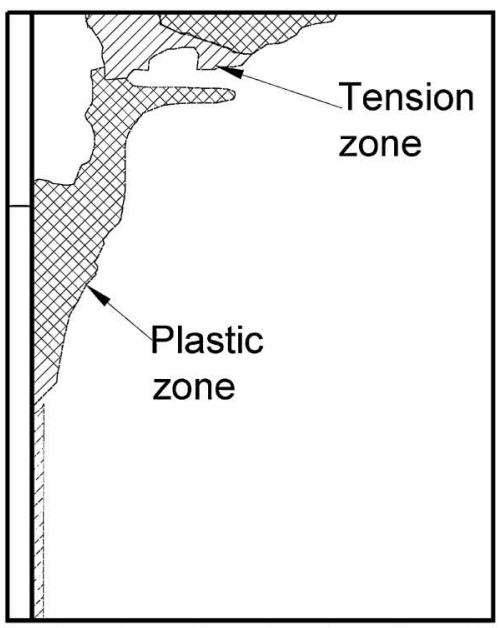

(b) Plastic zones at pullout displacement ratio $\delta_{v} / r_{0}=0.7$

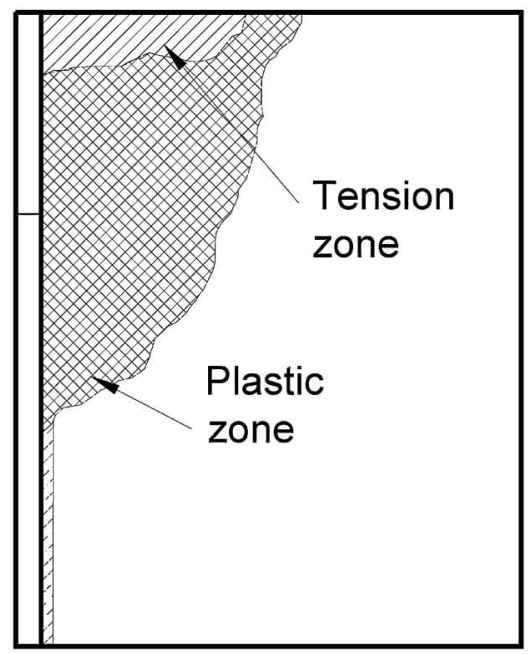

(d) Plastic zones at pullout displacement ratio $\delta_{v} / r_{0}=1.6$ (Failure)

Fig. 14. Calculated velocity fields and corresponding plastic zones during pullout (Test C)

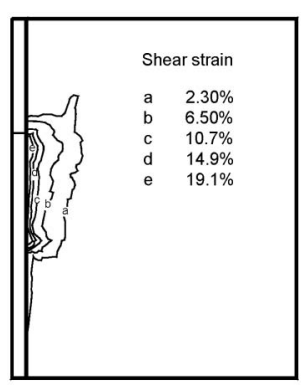

(a) Pullout displacement ratio of $\delta_{v} / r_{0}=0.7$

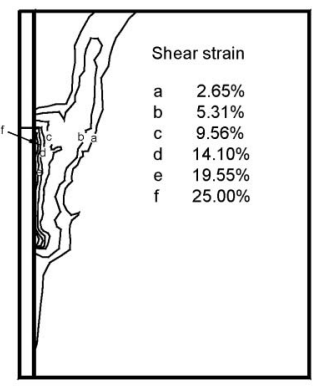

(b) Pullout displacement ratio of $\delta_{v} / r_{0}=1.6$ (Failure)
Fig. 15. Calculated shear strain contours in sand during pullout (Test C) dent parameters: (i) effective stress at the top of the anchor, $\sigma_{v}^{\prime}$, (ii) the slenderness ratio, $L / r$, (iii) the degree of cavity expansion, $\delta \mathrm{r} / r$, (iv) the interface strength, $\delta$, (v) the friction angle of the soil, $\phi^{\prime}$, (vi) the anchor weight, $W_{\mathrm{a}}$, and (vii) the membrane modulus, $E_{\mathrm{m}}$. For the tests described in this paper, $W_{\text {a }}$ was a small fraction of the ultimate anchor load, and the parameters $\sigma_{\mathrm{v}}^{\prime}$, and $E_{\mathrm{m}}$, were not varied. Thus, for a given $\delta$ and $\phi^{\prime}$, the following dimensionless parameter can be derived:

$$
\xi=(\delta \mathrm{r} / r)(L / r)
$$

where $r$ is the final radius after cavity expansion and $r=\delta \mathrm{r}$ $+r_{0}$.

Figure 18 summarizes $L_{\mathrm{e}} / L$ versus the dimensionless parameter $\xi$ for all of the anchor tests. From the FE ana- 


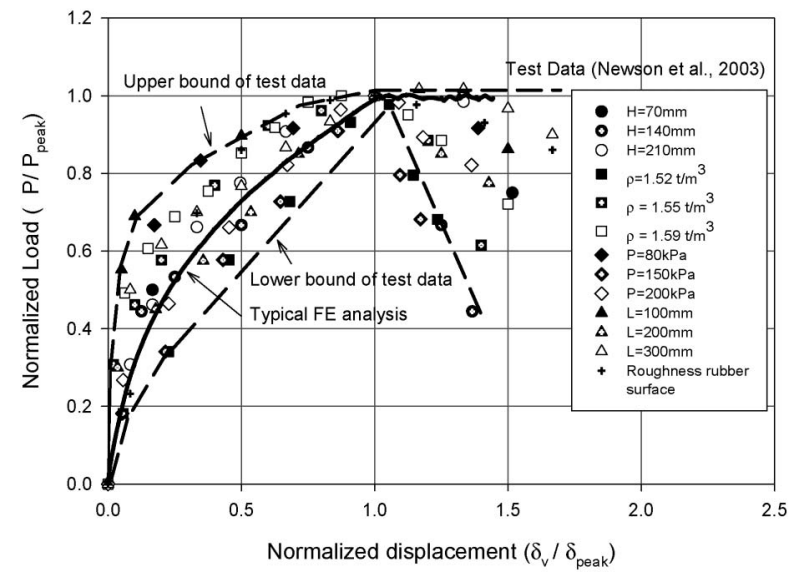

Fig. 16. Normalized relationship between force and displacement (all anchors)

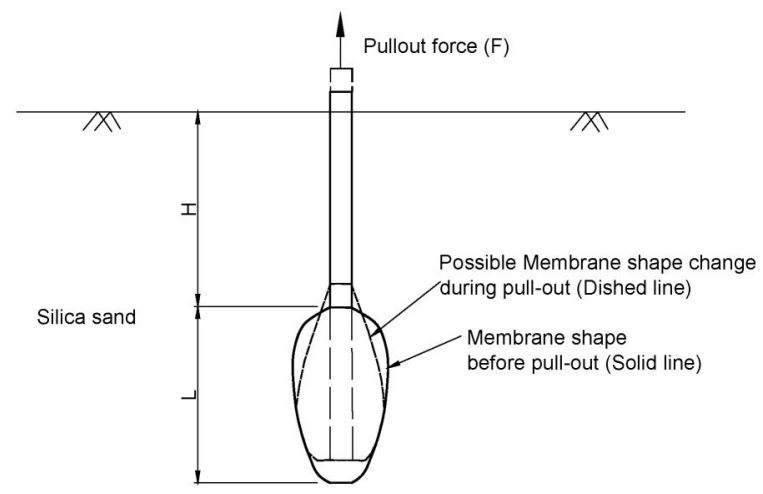

Fig. 17. Hypothesized shape change of the membrane during pullout

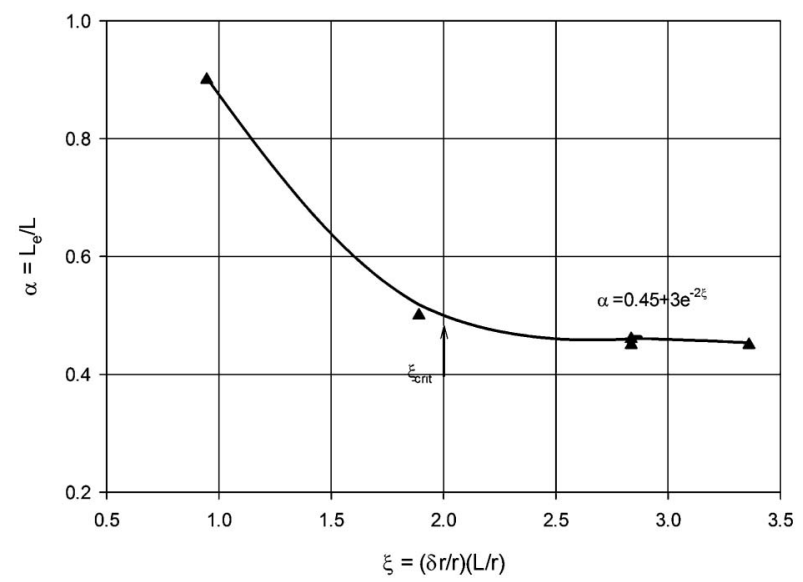

Fig. 18. Effective length ratio $L_{\mathrm{e}} / L$ versus dimensionless parameter, $\xi$ $=(\delta \mathbf{r} / r)(L / r)$

lyses, it appears that there is a good correlation between $\left(L_{\mathrm{e}} / L\right)$ and $\xi$ where:

$$
\left(L_{\mathrm{e}} / L\right)=0.45+3.0 e^{-2.0 \xi}
$$

Thus, the data suggests a transition from short anchor behaviour where the full anchor length is effective at $\xi \leq 1$ to long anchor behaviour for $\xi \geq 2.5$ where increasing the anchor length does not significantly influence the pullout capacity.

\section{CONCLUSIONS}

Based on the numerical study of the behaviour of an inflatable anchor system in sand, the following conclusions can be drawn:

1) The PLAXIS FE model can approximately simulate the behavior of the inflatable anchors in cohensionless soil. The model was however not able to account for geometric nonlinearity during the anchor pullout stage requiring adoption of an effective length for each anchor.

2) The pullout capacity of this type of inflated anchor is strongly influenced by the response of the embedment soil at yield.

3) The FE model consistently under predicted displacements mobilized at the ultimate load. This is most likely due to membrane distortions and membrane nonlinearity, which were not accounted for in the analysis.

4) Adoption of an effective length for each anchor permitted a consistent interpretation of the pullout response. As such, it is concluded that membrane distortions during pullout and consequent changes in the geometry of the anchor are important.

5) The normalized effective length $\left(L_{\mathrm{e}} / L\right)$ is proportional to the dimensionless parameter $\xi$. The overall response suggests that short anchor behaviour occurs for $\xi<1$ wherein the full anchor length is active in resisting the pullout loads.

6) There is a transition from short anchor behaviour to long anchor behaviour wherein additional anchorage length does not improve the pullout capacity. For the test conditions considered, long anchor behaviour occurs for $\xi \geq 2.5$.

7) Lastly, future numerical analysis of inflatable anchor behaviour should account for the non-linear biaxial behavior of elastomers and the shape change of the membrane during pullout.

\section{ACKNOWLEDGEMENTS}

The authors would like to acknowledge the contributions of Stephen Gallacher, Fraser Smith and the staff of the University of Dundee, and Paul Bruning of Acergy Northern Europe and Canada during the early stage of this project.

\section{REFERENCES}

1) Ahmad, S., Davies, T. G. and Manolis, G. D. (2005): Viscoelastic analysis of piles and pile groups, International Journal for Numerical and Analytical Methods in Geomechanics, 9(3), 237-252.

2) Bhattacharya, S., Madabhushi, S. P. G. and Bolton, M. (2003): Pile Instability during earthquake liquefaction, ASCE Engineering Mechanics Conference (EM2003), Seattle, 16-18th July, 2003.

3) Bolton, B. D. (1986): The strength and dilatancy of sands, Gèotechnique, 36(1), 65-78. 
4) Brinkgreve, R. B. J., Al-Khoury, R., Bakker, K. J., Bonnier, P. G., Brand, P. J. W., Broere, W., Burd, H. J., Soltys, G., Vermeer, P. A. and Haag, D. D. (2002): PLAXIS: Finite element code for soil and rock analyses (Version 8.0).

5) Degil', G. O. (1991): Determination of bearing capacity of singleanchor foundations in soil, taking into account the "embedment wave", Soil Mechanics and Foundation Engineering, 28(5), 201-203.

6) Gallacher, T. S. (2000): Novel anchoring systems for remotely operated vehicles, Honors Year Dissertation, The 4th year B. Eng. Thesis, Department of Civil Engineering, the University of Dundee, Scotland, UK.

7) Hughes, J. M. O., Wroth, C. P. and Windle, D. (1977): Pressuremeter tests in sands, Géotechnique, 27(4), 455-477.

8) Indraranta, B. (1991): Development of negative skin frictions on driving piles in soft Bangkok clay-Reply, Can. Geotech. J., 30, 890-891.

9) Iskander, M., El-Gharbawy, S. and Olson, R. (2002): Performance of suction caissons in sand and clay, Can. Geotech. J., 39, 576-584.

10) Kanakapura, S., Rao, S. and Kumar, J. (1994): Vertical uplift capacity of horizontal anchors, Journal of Geotechnical Engineer- ing, ASCE, 120(7), 1134-1147.

11) Newson, T., Bruning, P. and Gallagher, S. (2003): An experimental study of inflatable offshore anchors, ISOPE Conference 2003, Hawaii, Paper \#2003-JSC-127.

12) Newson, T., Hinchberger, S. and Liang, Y. (2007): Detailed analysis of inflatable anchors in cohesionless soil, Geotechnical Research Center Report, No. GEOT-05-07, the University of Western Ontario, London, Ontatio, Canada, 35-50.

13) Nihar, P. and Prabhaka, P. (2006): Model pile groups under oblique pullout loads-an investigation, Geotechnical and Geological Engineering, 24(2), 265-282.

14) Schanz, T., Vermeer, P. A. and Bonnier, P. G. (1999): The hardening soil model: formulation and verification, In Beyond 2000 in Computation Geotechnics: 10 Years of Plaxis, Rotterdam 1-16.

15) Ueno, K. (1998): Methods for preparation of sand samples, Proc. Centrifuge '98, Singapore, 1049-1055.

16) Wald, F., Sokol, Z. and Jaspart, J. P. (2008): Base plate in bending and anchor bolt in tension, Heron, 53(1/2).

17) $\mathrm{Yu}, \mathrm{S}$. H. and Houlsby, T. G. (1991): Finite cavity expansion in dilatant soils: loading analysis, Géotchnique, 41(2), 173-183. 